London

lauriefclarke@protonmail.com

Cite this as: BMJ2021;373:n1170 http://dx.doi.org/10.1136/bmj.n1170 Published: 25 May 2021

\title{
SOCIAL MEDIA
}

\section{Covid-19: Who fact checks health and science on Facebook?}

Overwhelming pressure from governments and the public has compelled social media platforms to take unprecedented action on what users share online in the pandemic. But who fact checks the fact checkers? Laurie Clarke reports

\section{Laurie Clarke freelance journalist}

In a move likened to the way governments have assumed emergency powers in response to the covid pandemic, Facebook has removed 16 million pieces of its content and added warnings to around 167 million. YouTube has removed more than 850000 videos related to "dangerous or misleading covid-19 medical information.”

While a portion of that content is likely to be wilfully wrongheaded or vindictively misleading, the pandemic is littered with examples of scientific opinion that have been caught in the dragnet-resulting in their removal or de-prioritisation, depending on the platform and context. This underscores the difficulty of defining scientific truth, prompting the bigger question of whether social media platforms such as Facebook, Twitter, Instagram, and YouTube should be tasked with this at all.

"I think it's quite dangerous for scientific content to be labelled as misinformation, just because of the way people might perceive that," says Sander van der Linden, professor of social psychology in society at Cambridge University, UK. "Even though it might fit under a definition [of misinformation] in a very technical sense, I'm not sure if that's the right way to describe it more generally because it could lead to greater politicisation of science, which is undesirable.”

\section{How fact checking works}

The past decade has seen an arms race between users who peddle disinformation (intentionally designed to mislead) or unwittingly share misinformation (which users don't realise is false) and the social media platforms that find themselves charged with policing it, whether they want to or not. ${ }^{1}$

When The BMJ questioned Facebook, Twitter, and YouTube (which is owned by Google) they all highlighted their efforts to remove potentially harmful content and to direct users towards authoritative sources of information on covid-19 and vaccines, including the World Health Organization and the US Centers for Disease Control and Prevention. Although their moderation policies differ slightly, the platforms generally remove or reduce the circulation of content that disputes information given by health authorities such as WHO and the CDC or spreads false health claims that are considered harmful, including incorrect information about the dangers of vaccines.
But the pandemic has seen a shifting patchwork of criteria employed by these companies to define the boundaries of misinformation. This has led to some striking U turns: at the beginning of the pandemic, posts saying that masks helped to prevent the spread of covid-19 were labelled "false"; now it's the opposite, reflecting the changing nature of the academic debate and official recommendations.

Twitter manages its fact checking internally. But Facebook and YouTube rely on partnerships with third party fact checkers, convened under the umbrella of the International Fact-Checking Network-a non-partisan body that certifies other fact checkers, run by the Poynter Institute for Media Studies, a non-profit journalism school in St Petersburg, Florida. Poynter's top donors include the Charles Koch Institute (a public policy research organisation), the National Endowment for Democracy (a US government agency), and the Omidyar Network (a "philanthropic investment firm"), as well as Google and Facebook. Poynter also owns the Tampa Bay Times newspaper and the high profile fact checker PolitiFact. The Poynter Institute declined The BMJ's invitation to comment for this article.

For scientific and medical content the International Fact-Checking Network involves little known outfits such as SciCheck, Metafact, and Science Feedback. Health Feedback, a subsidiary of Science Feedback, handpicks scientists to deliver its verdict. Using this method, it labelled as "misleading" a Wall Street Journal opinion article ${ }^{2}$ predicting that the US would have herd immunity by April 2021, written by Marty Makary, professor of health policy and management at John Hopkins University in Baltimore, Maryland. This prompted the newspaper to issue a rebuttal headlined "Fact checking Facebook's fact checkers," arguing that the rating was "counter-opinion masquerading as fact checking."3 Makary hadn't presented his argument as a factual claim, the article said, but had made a projection based on his analysis of the evidence.

A spokesperson for Science Feedback tells The BMJ that, to verify claims, it selects scientists on the basis of "their expertise in the field of the claim/article." They explain, "Science Feedback editors usually start by searching the relevant academic literature and identifying scientists who have authored articles on related topics or have the necessary expertise to assess the content." 
The organisation then either asks the selected scientists to weigh in directly or collects claims that they've made in the media or on social media to reach a verdict. In the case of Makary's article it identified 20 relevant scientists and received feedback from three.

\section{"Follow the science"}

The contentious nature of these decisions is partly down to how social media platforms define the slippery concepts of misinformation versus disinformation. This decision relies on the idea of a scientific consensus. But some scientists say that this smothers heterogeneous opinions, problematically reinforcing a misconception that science is a monolith.

This is encapsulated by what's become a pandemic slogan: "Follow the science.” David Spiegelhalter, chair of the Winton Centre for Risk and Evidence Communication at Cambridge University, calls this "absolutely awful," saying that behind closed doors scientists spend the whole time arguing and deeply disagreeing on some fairly fundamental things.

He says: "Science is not out in front telling you what to do; it shouldn't be. I view it much more as walking along beside you muttering to itself, making comments about what it's seeing and making some tentative suggestions about what might happen if you take a particular path, but it's not in charge."

The term "misinformation" could itself contribute to a flattening of the scientific debate. Martin Kulldorff, professor of medicine at Harvard Medical School in Boston, Massachusetts, has been criticised for his views on lockdown, which tack closely to his native Sweden's more relaxed strategy. ${ }^{4}$ He says that scientists who voice unorthodox opinions during the pandemic are worried about facing "various forms of slander or censoring ... they say certain things but not other things, because they feel that will be censored by Twitter or YouTube or Facebook.” This worry is compounded by the fear that it may affect grant funding and the ability to publish scientific papers, he tells The BMJ.

The binary idea that scientific assertions are either correct or incorrect has fed into the divisiveness that has characterised the pandemic. Samantha Vanderslott, a health sociologist at the University of Oxford, UK, told Nature, "Calling out fake stories can raise your profile.” In the same article Giovanni Zagni, director of the Italian fact checking website Facta, noted that "you can build a career" on the basis of becoming "a well respected voice that fights against bad information." 5

But this has fed a perverse incentive for scientists to label each other's positions misinformation or disinformation. ${ }^{6}$ Van der Linden likens this to how the term "fake news" was weaponised by Donald Trump to silence his critics. He says, "I think you see a bit of the same with the term 'misinformation,' when there's science that you don't agree with and you label it as misinformation."

Health Feedback's website says that it won't select scientists to verify claims if they've undermined their credibility by "propagating misinformation, whether intentionally or not.” In practice, this could create a Kafkaesque situation where scientists are precluded from offering their opinion as part of the fact checking process if they expressed an opinion that Facebook labelled misinformation. Strengthening the echo chamber effect is the fact that Health Feedback sometimes verifies claims by looking at what scientists have said on Twitter or in the media.

\section{Scientific "truth"}

Van der Linden says that it's important for people to understand that in the scientific domain 'there's uncertainty, there's debate, and it's about the accumulation of insights over time and revising our opinions as we go along." Healthy debate helps to separate the wheat from the chaff. Jevin West, associate professor in the Information School at the University of Washington in Seattle, says that social media platforms should therefore be "extra careful when it comes to debates involving science.” He explains: "The institution of science has developed these norms and behaviour to be self-corrective. So, for [social media platforms] to step into that conversation, I think it's problematic.”

Experts who spoke to The BMJ emphasised the near impossibility of distinguishing between a minority scientific opinion and an opinion that's objectively incorrect (misinformation). Spiegelhalter says that this would constitute a difficult "legalistic judgment about what a reasonable scientific opinion would be ... I've got my own criteria that I use to decide whether I think something is misleading, but I find it very difficult to codify."

Other scientists worry that, if this approach to scientific misinformation outlives the pandemic, the scientific debate could become worryingly subject to commercial imperatives. Vinay Prasad, associate professor at the University of California San Francisco, argued on the MedPage Today website: "The risk is that the myriad players in biomedicine, from large to small biopharmaceutical and [medical] device firms, will take their concerns to social media and journal companies. On a topic like cancer drugs, a tiny handful of folks critical of a new drug approval may be outnumbered 10:1 by key opinion leaders who work with the company."7 Thus the majority who speak loudest, most visibly, and with the largest number online, may be judged "correct" by the public-and, as the saying goes, history is written by the victors.

Social media companies are still experimenting with the new raft of measures introduced since last year and may adapt their approach. Van der Linden says that the talks he's had with Facebook have focused on how the platform could help foster an appreciation of how science works, "to actually direct people to content that educates them about the scientific process, rather than labelling something as true or false.”

This debate is playing out against a wider ideological struggle, where the ideal of "truth" is increasingly placed above "healthy debate." Kulldorff says: "To remove things in general, I think is a bad idea. Because even if something is wrong, if you remove it there's no opportunity to discuss it.” For instance, although he favours vaccination in general, people with fears or doubts about the vaccines used should not be silenced in online spaces, he says. "If we don't have an open debate within science, then that will have enormous consequences for science and society."

There are concerns that this approach could ultimately undermine trust in public health. In the US, says West, trust in the government and media is falling. He explains, "Science is still one of the more trusted institutions, but if you start tagging and shutting down conversation within science, to me that's even worse than the actual posting of these individual articles.”

Competing interests: I have read and understood BMJ policy on declaration of interests and have no relevant interests to declare.

Provenance and peer review: Commissioned, not externally peer reviewed.

Wardle C, Singerman E. Too little, too late: social media companies' failure to tackle vaccine misinformation poses a real threat. BMJ2021;372:n26. doi: 10.1136/bmj.n26 pmid: 33478950 Makary M. We'll have herd immunity by April. Wall Street /2021 Feb 18.

https://www.wsj.com/articles/well-have-herd-immunity-by-april-11613669731?mod=article_inline. Wall Street Journal Editorial Board. Opinion: Fact-checking Facebook's fact checkers. Wall Street J2021 Mar 5. https://www.wsj.com/articles/fact-checking-facebooks-fact-checkers-11614987375. 
4 Habib H. Has Sweden's controversial covid-19 strategy been successful?BMJ2020;369:m2376. doi: 10.1136/bmj.m2376 pmid: 32532807

5 Fleming N. Coronavirus misinformation, and how scientists can help to fight it. Nature 2020 Jun 17. https://www.nature.com/articles/d41586-020-01834-3.

6 Bhopal R, Munro APS. Scholarly communications harmed by covid-19. BMJ 2021;372:n742. doi: 10.1136/bmj.n742 pmid: 33753356

7 Prasad V. Op-ed: We should all care about censorship in science. MedPage Today. 30 Nov 2020 https://www.medpagetoday.com/blogs/vinay-prasad/89932.

This article is made freely available for use in accordance with BMJ's website terms and conditions for the duration of the covid-19 pandemic or until otherwise determined by BMJ. You may use, download and print the article for any lawful, non-commercial purpose (including text and data mining) provided that all copyright notices and trade marks are retained. 